20

\title{
Оптическая цифровая регистрация седиментации эритроцитов и ее моделирование в форме коллективного процесса
}

\author{
() В.А. Дубровский ${ }^{1}$, К.Н. Дворецкий ${ }^{1}$, С.В. Марков ${ }^{1,2}$, Е.П. Карпочева ${ }^{3}$, В.В. Тучин ${ }^{2,4,5}$ \\ ${ }^{1}$ Саратовский государственный медицинский университет, \\ 410012 Саратов, Россия \\ ${ }^{2}$ Саратовский национальный исследовательский государственный университет, \\ 410012 Саратов, Россия \\ ${ }^{3}$ Саратовский региональный центр переливания крови, \\ 410033 Саратов, Россия \\ ${ }^{4}$ Институт проблем точной механики и управления РАН, \\ 410028 Саратов, Россия \\ ${ }^{5}$ Национальный исследовательский Томский государственный университет, \\ 634050 Томск, Россия \\ e-mail: doubrovski43@yandex.ru
}

Поступила в редакцию 15.12.2018 г.

В окончательной редакции 01.01.2019 г.

Принята к публикации 31.01.2019 г.

С помощью цифровой видеотехники исследуется зависимость скорости седиментации донорской крови от ее процентного содержания в образце (степени ее разведения физраствором) в пределах от 0.25 до $100 \%$ (цельная, неразведенная кровь). При этом за скорость седиментации крови принималось отношение величины перемещения границы седимент-супернатант за единицу времени. В случаях регистрации различных скоростей перемещения этой границы в заданном объеме кюветы производилось их пространственное усреднение. Экспериментально обнаружено существенное возрастание скорости оседания крови при больших уровнях ее разведения, а также, наоборот, при концентрациях крови в физрастворе, близких к цельной. В то же время скорость седиментации крови снижалась в несколько раз при ее содержании в пределах 30-50\%. Экспериментально показано, что при варьировании в широких пределах содержания крови в физрастворе седиментация взвеси происходит равномерно практически для любой концентрации крови в смеси. Или иначе, в процессе седиментации одной пробы крови заданного разведения в физрастворе скорость оседания не меняется со временем. Полученные экспериментально результаты позволили построить теоретическую модель оседания крови для двух случаев: 1) седиментация свободных эритроцитов (сильное разведение крови) и 2) оседание эритроцитарных агрегатов (слабое разведение крови, вплоть до цельной крови). Особенность модели заключается в том, что предложено рассматривать оседание клеток и/или их агрегатов в виде коллективного эффекта, а не в традиционной форме оседания индивидуальных или взаимодействующих друг с другом частиц. Показано, что данная модель при использовании некоторых эмпирических констант дает удовлетворительное совпадение с экспериментальными закономерностями. Проведенное исследование представляется полезным для понимания процесса седиментации эритроцитов.

DOI: $10.21883 /$ OS.2019.05.47670.20-19

\section{1. Введение}

Явление расслоения крови на клеточную и плазменную фракции, а также зависимость скорости этого процесса от типов заболеваний было обнаружено Эдмундом Биернаки в 1894 г. [1]. Однако лишь в 1921 г. это явление нашло применение в медицинских диагностических целях после того, как Альф Вестергрен предложил способ измерения скорости оседания эритроцитов в цельной крови в вертикально установленной узкой трубке [2]. С тех пор анализ скорости оседания эритроцитов (СОЭ)

\footnotetext{
* The 22nd Annual Conference Saratov Fall Meeting 2018 (SFM'18): VI International Symposium „Optics and Biophotonics“ and XXII International School for Junior Scientists and Students on Optics, Laser Physics \& Biophotonics, September 24-29, 2018, Saratov, Russia. https://www.sgu.ru/structure/fiz/saratov-fall-meeting/previousconferences/sara
}

остается одним из самых надежных, традиционных тестов в клинической лабораторной практике [3]. В то же время совершенствование этого диагностического метода, изучение процесса седиментации крови, лежащего в основе метода, продолжается и поныне. Так, в [4-7] осуществлены клинические исследования, наблюдение пациентов и установление связи величин СОЭ с типом и характером заболеваний. Изучение влияния различных биохимических, иммунологических и физических факторов на скорость седиментации эритроцитов и их ассоциатов (экспериментальное моделирование) реализовано в $[7,8-14]$. Работы $[15,16]$ посвящены усовершенствованию метода СОЭ, а исследования [8,12-14,17-22] физическому и математическому моделированию механизмов, приводящих к явлению оседания клеток и их комплексов. 
В то же время нельзя не отметить некоторую неоднозначность этого метода исследования. Так, стандартные значения СОЭ „иногда могут наблюдаться в терминальных стадиях заболевания, а при, казалось бы, легких заболеваниях величина СОЭ может быть весьма высокой“ [8]. Такая диагностическая неоднозначность метода СОЭ, несмотря на длительное и широкое его применение, обусловлена, как ни странно, недостаточной его проработкой [23]. Эта же причина приводит к ограниченному использованию потенциальных возможностей этого метода диагностики [8].

Существует несколько подходов к описанию механизмов седиментации крови. Наиболее упрощенным является анализ индивидуального осаждения эритроцитов (RBC - red blood cell) в представлении клеток в форме шара. Такой подход основан на использовании закона Стокса [24].

Однако в цельной крови или слабых ее растворах эритроциты расположены чрезвычайно близко друг к другу - расстояние между соседними эритроцитами меньше размеров самих эритроцитов. Это приводит к необходимости учитывать влияние соседних эритроцитов на процесс седиментации анализируемой клетки $[17,25]$. Заметим, что в процессе седиментации эритроцитов формируется встречный поток, который притормаживает движение эритроцитов за счет силы трения $[13,17]$.

Считается, что стартом к наиболее интенсивной седиментации крови является формирование в образце „монетных столбиков“ и вслед за тем эритроцитарных агрегатов $[8,9,11-13,17,19,21,25,26]$. Описание седиментации RBC-агрегатов возможно на тех же принципах, что и оседание одиночных эритроцитов. Однако в отличие от идентичных RBC-шаров эритроцитарные агрегаты имеют разные размеры, а следовательно, необходимо вводить распределение агрегатов по размерам (эквивалентных шаров по диаметрам) [25]. Естественно, даже при таком модельном процессе оседание крови не происходит по типу „сначала формирование агрегатов определенных размеров и их распределения по размерам, а затем оседание агрегатов во времени“. Эти процессы происходят одновременно, попытка моделирования такой конструкции предпринята в [25]. Однако авторы [25] отмечают острую необходимость экспериментальной проверки сделанных теоретических построений.

Помимо „микроскопического“ подхода к анализу седиментации крови, когда рассматривается оседание эритроцитов индивидуально или с учетом эритроцитарного окружения, или с учетом явления RBC-агрегации, существует иной механизм оседания крови, основанный на „сетевой“ модели строения образцов крови модели С.Д. Балаховского [27]. В образцах крови им была обнаружена трехмерная клеточная сеть, состоящая из разветвляющихся „монетных столбиков“. Тогда седиментация крови может рассматриваться как „проседание петель“ этих сетей и их сближение друг с другом, а не седиментация отдельных клеток и их ассоциатов [8]. Отметим, что модель С.Д. Балаховского предполагает возможность коллективной седиментации крови: „проседание“ одной петли сетей может стимулировать „проседание“ других, связанных с первой. И, наконец, представляется важным отметить, что в рамках модели С.Д. Балаховского встречный поток проходит сквозь отверстия в сети, оказывая на эритроцитарную сеть тормозящее влияние. Однако, к сожалению, нам не удалось найти работы по математическому моделированию седиментации крови в рамках этой модели.

Отметим еще одну особенность рассмотренных работ. В подавляющем большинстве они направлены на исследование процесса седиментации цельной или слабо разведенной физраствором крови. Их основная цель изучение особенностей СОЭ как диагностического метода. Однако явление седиментации эритроцитов и их ассоциатов (а возможно, и других объектов биологического и небиологического происхождения) может использоваться и по другим направлениям, в частности для разработки акустооптического метода определения групповой принадлежности образцов крови [28-33]. В этих работах степень разведения крови в физрастворе составляла величину порядка 1:100 и даже больше (до 1:600). В [14] зависимость смещения границы ,раствор плазмыэритроцитарная масса“ от времени наблюдения оседания крови измерялась, начиная от цельной крови и вплоть до концентраций крови в физрастворе 33\%. При этом по мере разбавления крови скорость ее седиментации снижалась. Представляет интерес поведение скорости седиментации крови при столь сильных ее разведениях как в [28-33]. Будет ли скорость седиментации продолжать снижаться с увеличением степени ее разведения?

В целом, можно утверждать, что все известные нам математические модели оседания эритроцитов и их ассоциатов основаны на принципах микроскопии - анализ движения одиночного эритроцита или агрегата с использованием закона Стокса с учетом или без учета влияния окружающих клеток, ассоциатов. Цель настоящей работы - на основе оптической цифровой фоторегистрации исследовать зависимость скорости седиментации крови от степени ее разведения физраствором в широких пределах, а также определить кинетику седиментации крови при различных начальных концентрациях эритроцитов в пробе. Кроме того, на основе полученных экспериментальных результатов попытаться построить макроскопическую модель седиментации крови, когда анализируется не индивидуальное оседание эритроцита или RBC-агрегатов, а интегральная седиментация крови в виде квазисплошного слоя, заполненного свободными эритроцитами и/или их агрегатами. 

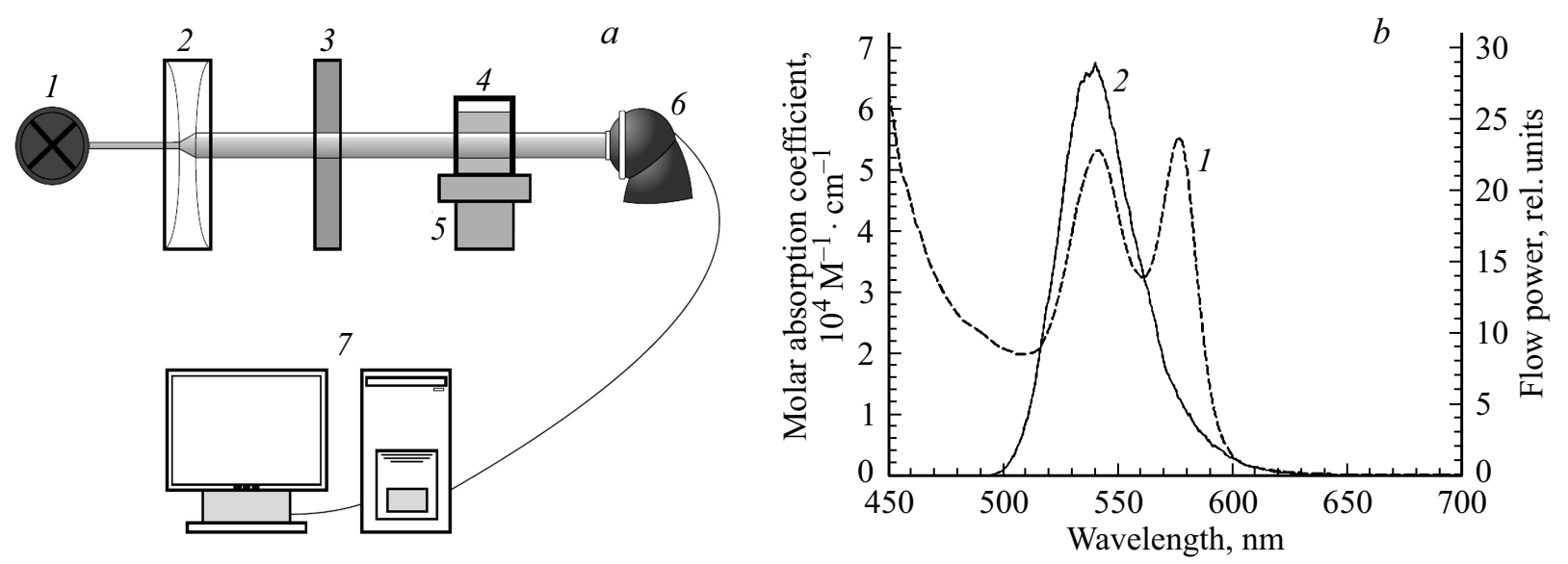

Рис. 1. Схема экспериментальной установки $(a)$ и спектры зондирующего излучения и биообъекта $(b):(a) 1-$ источник света (светодиод), 2 - телескопическая система линз, 3 - светофильтр, 4 - кювета с исследуемым раствором, 5 - столик для крепления кювет, 6 - цифровая камера, 7 - компьютер; $(b) 1-$ спектр поглощения гемоглобина (левая ось ординат), $2-$ спектр излучения светодиода (правая ось ординат).

\section{2. Седиментация эритроцитов - эксперимент}

\section{1. Условия и техника проведения эксперимента}

Эксперименты по регистрации процесса седиментации раствора крови проводились на установке, изображенной на рис. 1.

Размеры внутренней полости прямоугольной кюветы $10 \times 10 \times 45 \mathrm{~mm}$. Степень разведения цельной донорской крови физраствором варьировалась: 0.25, 0.5, 1, 5, $10,20,30,50,60,80$ и 100\% (цельная кровь). Легко видеть, что с учетом размеров идентичных кювет выполнение лишь одной серии экспериментов с вышеперечисленными уровнями разведения крови требовало порядка $150 \mathrm{ml}$ донорской крови. Поэтому для получения столь значительного суммарного объема крови ее образцы разных доноров смешивались, однако все смешиваемые пробы были одной группы по системе АВ0. Стоит заметить, что общее количество подобных экспериментальных серий составило 8 , а длительность каждой из них, как это будет показано ниже, измерялось часами. В отличие от [14], где в цельную кровь добавлялся физраствор, здесь, наоборот, в физраствор добавлялась порция донорской крови, а затем взвесь перемешивалась с помощью микродозатора. Естественно, вначале в течение до 20-30 min (в зависимости от степени разведения крови) взвесь находилась в турбулентном состоянии, и лишь затем происходило равномерное оседание крови. Заметим, что здесь и далее мы стараемся избегать фразы „седиментация эритроцитов“, используем „седиментация крови“. Это обусловлено тем, что в экспериментах степень разведения крови варьируется в широких пределах, включая пробы с высоким содержанием эритроцитов, а следовательно, с присутствием эритроцитарных агрега- тов. Поэтому, на наш взгляд, выражение „седиментация эритроцитов“ правильно использовать в случаях сильного разведения крови, когда вероятность образования эритроцитарных агрегатов мала. Как будет показано экспериментально ниже, такое пороговое разведение крови физраствором составляет примерно 30\%.

Биообъект зондировался коллимированным излучением светодиода типа LXHL-G1S, спектр которого соответствовал спектру поглощения гемоглобина в зеленой области (рис. $1, b)$. Режим питания светодиода: напряжение $3 \mathrm{~V}$, сила тока 0.3 А. Подбор спектра зондирующего светового излучения был продиктован необходимостью повышения контрастности фотоизображения границы „раствор плазмы-взвесь эритроцитов“, что способствует повышению точности регистрации седиментации крови.

После прохождения сквозь образец зондирующий луч попадал на полихромную web-камеру Logitech Quick Cam. Полученные цифровые фотокадры (файлы) подвергались разложению на RGB-компоненты, причем анализировалась лишь G-составляющая. Выбор G-компоненты фотоизображения сопряжен со спектром поглощения света гемоглобином в зеленой области и, естественно, со спектром зондирующего излучения светодиода (рис.1,b).

Техника эксперимента заключалась в следующем. Серия из 4 кювет с разной степенью разведения крови устанавливалась на столик для крепления кювет; образцы одновременно просвечивались зондирующим лучом, а фотоизображение в виде ролика регистрировалось с помощью видеокамеры. Одномоментная регистрация нескольких образцов растворов крови без их технического перемещения диктовалась необходимостью избежать нежелательного встряхивания образцов в ходе эксперимента. После проведения данной серии опытов подобный эксперимент повторялся, но для кювет с иным процентным содержанием крови в физрастворе. Опыты 

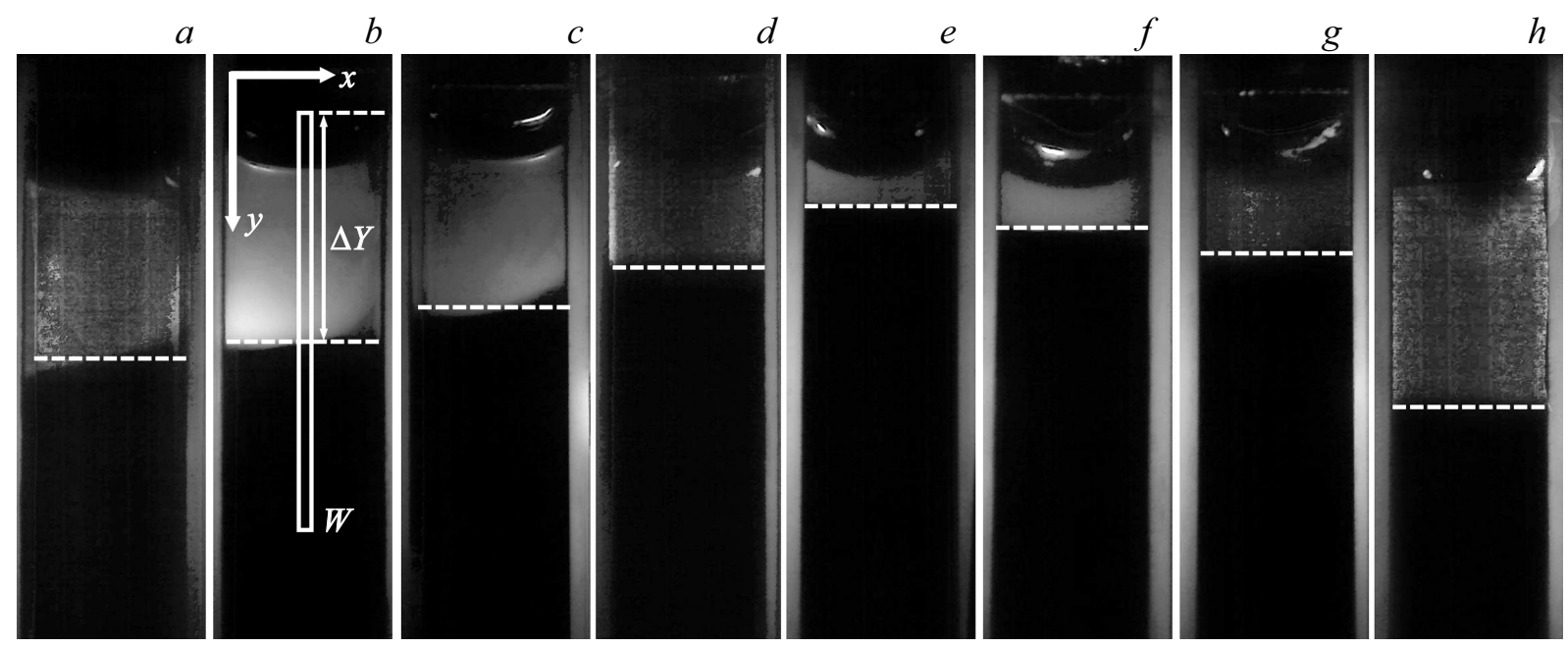

Рис. 2. Фото кювет с образцами крови, разведенной физраствором в соотношении: $0.25(a), 0.5(b), 1(c), 10(d), 30(e), 60(f)$, $80(g)$ и $100 \%(h)$. Фотоизображения соответствуют седиментации крови на 120 -й минуте. На рис. $2, b$ показано: прямоугольная рамка $W$ - область обработки фотоизображения для нахождения границы „раствор плазмы-эритроцитарная взвесь“; величина $\Delta Y$ - смещение границы „раствор плазмы-эритроцитарная взвесь“ к данному моменту времени.

в виде серий проводились с образцами крови типа $A_{\beta}$ или $B_{\alpha}$.

\section{2. Экспериментальные результаты}

Оседание крови при разных степенях ее разведения демонстрируют фотоизображения на рис. 2. Как отмечалось выше, опыты, подобные рис. 2, проводились неоднократно. При этом от опыта к опыту абсолютные величины скоростей седиментации для данной концентрации крови в физрастворе могли несколько варьировать, однако представленные на рис. 2 закономерности неизменно повторялись. Из рис. 2 следует, что максимальные значения скорости седиментации крови соответствуют образцам либо сильно разбавленным (0.25\%), либо практически цельной крови (100\%). Минимум скорости седиментации приходится на $30 \%$ содержание крови во взвеси.

Фотоизображения, подобные рис. 2, обрабатывались компьютерным образом: в рамках зоны $W$ проводилось попиксельное (вдоль оси $X$ ) усреднение величины яркости изображения $B$ (brightness) для каждой строки с координатой вдоль оси $Y$. В результате определялась зависимость средней по строкам $X$ яркости фотоизображения $B_{\text {mean }}$ кюветы с раствором донорской крови от координаты $Y$ в различные моменты времени в процессе седиментации. Координата $Y=Y_{b}$, для которой $B_{\text {mean }}$ для заданного момента времени (избранного фотокадра видеоролика) обращается в нуль $\left(B_{\text {mean }}=0\right)$ и соотношение $B_{\text {mean }}=0$ сохраняться для последующих координат $\left(Y \geq Y_{b}\right)$, принимается за границу раздела „раствор плазмы-взвесь эритроцитов“ в данный момент времени. Такой подход позволял довольно точно определять положение границы „раствор плазмы-эритроцитарная масса“, а следовательно, скорость седиментации крови.
Скорость оседания крови определялась на основе кинетических кривых (рис. 3). Для каждого момента времени скорость оседания эритроцитов определялась как $\Delta Y / \Delta t$. Заметим, что некоторая хаотичность в поведении кривых $Y(t)$ на рис. 3 при малых временах наблюдения (20-30 $\mathrm{min})$ обусловлена турбулентностью движения эритроцитов в результате перемешивания крови в физрастворе. Однако в дальнейшем (при больших временах) зависимость $Y(t)$ в широких пределах носит практически линейный характер, следовательно, граница „раствор плазмы-взвесь эритроцитов“" движется с постоянной скоростью. Исключение составляет случай цельной крови: при определенных смещениях $\Delta Y$ граница „раствор плазмы-эритроцитарная масса“ достигает таких глубин по оси $Y$, где плотность взвеси крови и ее вязкость за счет высоких концентраций эритроцитов становятся значительными. Тогда зависимость скорости седиментации крови от времени претерпевает „насыщение“ кривая 8 рис. $3, b$.

Рисунок 3 показывает, что при больших концентрациях крови процесс седиментации стартует не с самого начала регистрации $(t=0)$, а с некоторым запаздыванием. Причем этот временной сдвиг тем меньше, чем больше концентрация крови в образце, По-видимому, это явление обусловлено тем, что для формирования эритроцитарных агрегатов, стимулирующих процесс седиментации, необходимо время. Представляется естественным, что это время тем меньше, чем концентрация эритроцитов больше. Подобное отсутствует при сильном разведении крови, так как вероятность образования эритроцитарных агрегатов чрезвычайно мала.

Другим и, возможно, параллельным объяснением временного сдвига седиментации крови является многократно наблюдаемое нами явление, ранее описанное в [8]. При седиментации крови в капилляре „столбик 




$b$

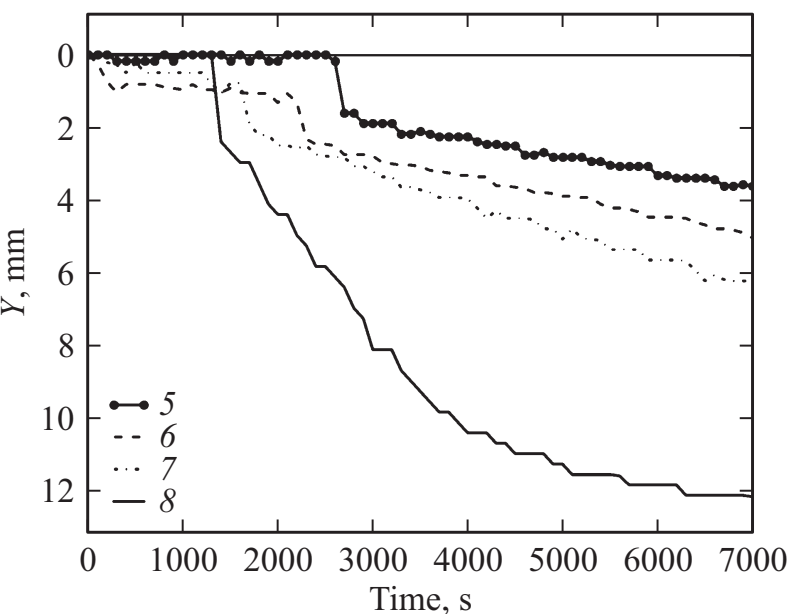

Рис. 3. Зависимость смещения (седиментации) уровня границы „раствор плазмы-взвесь эритроцитов“ $\Delta Y$ от времени наблюдения седиментации крови для различных ее концентраций во взвеси. Графики соответствуют степеням разведения крови в физрастворе: (a) $1-0.25 \%, 2-0.5 \%, 3-1 \%, 4-10 \%$; (b) $5-30 \%, 6-60 \%, 7-80 \%, 8-100 \%$.

красной крови отрывается от мениска, разделяющего кровь и воздух, не сразу, а после латентного периода, продолжительностью в ряде случаев в десятки минут“ [8]. Видеорегистрация с последующей компьютерной обработкой фотоизображений позволили нам количественно оценить этот временной сдвиг - от 4 до $40 \mathrm{~min}$ в зависимости от степени разведения крови. Кроме того, полученные фотоизображения указывали на возможный механизм наблюдаемого временного сдвига седиментации: при начальной стадии седиментации крови за счет встречного потока раствора плазмы между мениском жидкости и эритроцитарной массой образуется некий объем („пузырь“), заполненный раствором плазмы. Со временем объем этого „пузыря“ возрастает, область соприкосновения эритроцитарной массы с мениском уменьшается. В тот момент, когда эта область становится равной нулю, стартует процесс интенсивной седиментации крови. Наблюдаемое явление представляет интерес для дальнейшего детального исследования и моделирования.

Обработка фотоизображений (рис. 2) и кинетических кривых (рис. 3) позволила определить зависимость скорости оседания крови от степени ее разведения (рис. 4). Из рис. 4, $a$ видно, что для больших разведений крови $(0-30 \%)$ в отличие от малых $(30-100 \%)$ скорость седиментации крови возрастает с уменьшением ее концентрации (рис. 3 и фото на рис. 2). При этом интересно отметить, что скорость седиментации крови стремится к значениям скорости седиментации одиночных эритроцитов. С другой стороны, эксперименты показывают, что при больших концентрациях крови (30-100\%) скорость оседания возрастает с увеличением ее концентрации (рис. 4,a). Подобная зависимость на этом участке концентраций была рассчитана на основе результатов работы [14] (рис. 4,b). Представляет интерес найденное в [14] увеличение скорости седиментации крови при переходе от концентрации 50\% к концентрации 33\% (этот эффект нашел свое отражение на рис. $4, b$ ).

Заметим, что сопоставление результатов в диапазоне концентраций 30-100\%, представленных на рис. 4, $a$ и $4 b$, не совсем корректно, хотя бы потому, что образцы крови были разными, техника экспериментов была различной и, главное, результаты настоящей работы были получены в прямоугольной кювете, а результаты [14] в капилляре. В [13] отмечалось, что „картина седиментации крови в узких капиллярах отличается от подобной в прямоугольной кювете“. Однако в целом вырисовывается общая закономерность - скорость оседания крови принимает минимальные значения в диапазоне концентраций $\sim 30-50 \%$ и повышается при больших разведениях или, наоборот, при приближении взвеси к состоянию цельной крови.

\section{3. Моделирование седиментации крови при различной степени ее разведения физраствором}

\section{1. Общие принципы построения модели}

Из рис. 4 видно, что минимум скорости оседания крови приходится на концентрацию порядка 30-50\%. Оценки показывают, что в этой области среднестатистическое межклеточное расстояние $l$ оказывается соизмеримым с диаметром эритроцита $d_{\mathrm{er}}\left(l \approx d_{\mathrm{er}}\right)$. Напомним, что модель эритроцита в форме шара имеет диаметр порядка $5.5 \mu \mathrm{m}$. Естественно, при больших разведениях крови эритроцитарную взвесь можно рассматривать практически как совокупность индивидуальных, свободных эритроцитов, где вероятность их агрегации весьма мала. Так, при концентрации крови $0.25 \%$ (рис. 4) $l$ составляет 

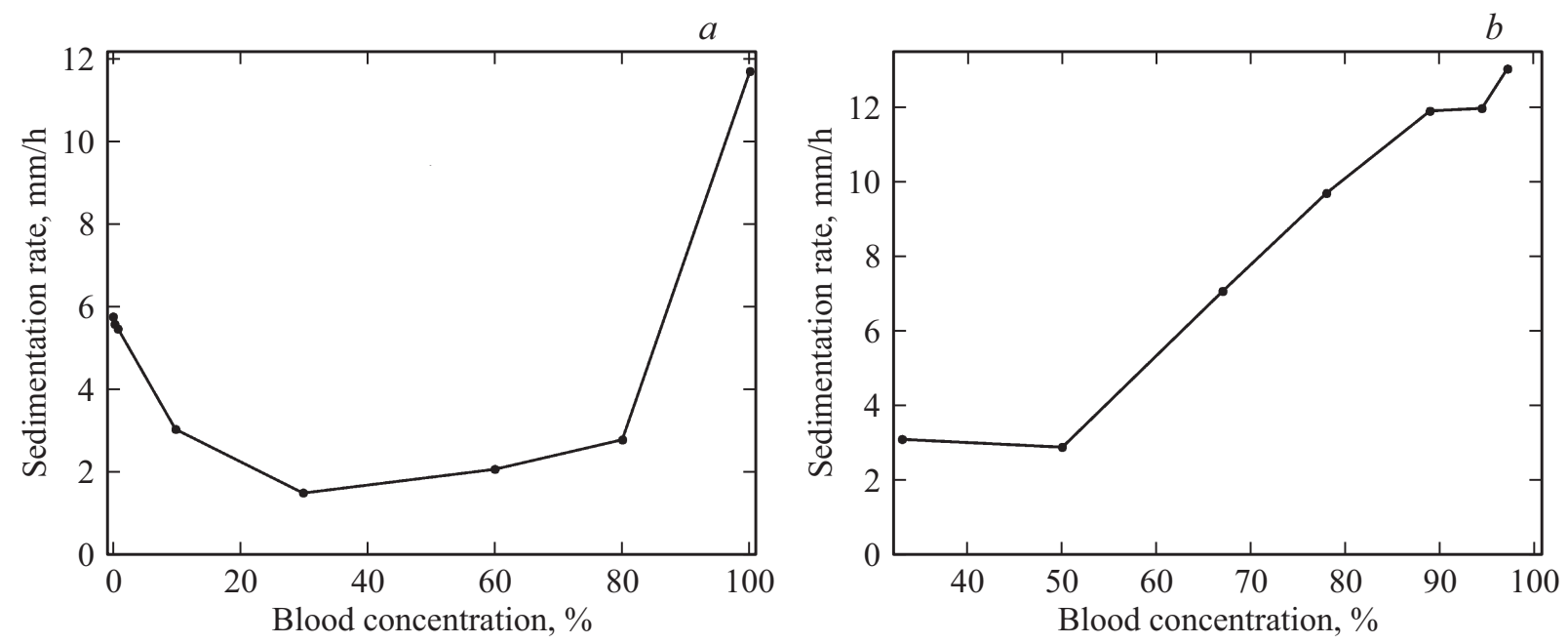

Рис. 4. Зависимость скорости седиментации крови от степени ее разведения физраствором $v(c)$ : $(a)$ оригинальные экспериментальные результаты; $(b)$ зависимость $v(c)$, качественно построенная по результатам работы [15].

около $40 \mu \mathrm{m}$, т.е. $l>d_{\mathrm{er}}$. С другой стороны, при малых разведениях крови расстояние между „эритроцитамишарами“ оказывается меньше их диаметра $\left(l<d_{\mathrm{er}}\right)$ : для цельной, не разбавленной крови расстояние $l$ составляет лишь $\sim 0.4 \mu \mathrm{m}$. В этом случае вероятность агрегации эритроцитов весьма велика. Вот почему при моделировании седиментации крови при разных степенях ее разведения целесообразно построить два варианта модели - для сильно разбавленных образцов крови (без учета процесса агрегации эритроцитов, разд. 3.2) и слабо разбавленных образцов, где эффект агрегации значителен (разд. 3.3).

В основу модели положим принцип коллективной седиментации эритроцитов и/или агрегатов. Выделим на поверхности цилиндрического столба жидкости некоторый диск высотой $h$, радиусом $R$, равным радиусу цилиндрического сосуда $(h \ll R)$. В отличие от традиционного „микроскопического подхода“, когда анализируют седиментацию одиночных, индивидуальных эритроцитов, будем рассматривать оседание эритроцитов в виде „эритроцитарного диска“ (макроскопический подход). Такой диск назовем эквивалентным. Авторы осознают некоторую некорректность: кювета в эксперименте была прямоугольной (раздел 2.1), а в модели процесса седиментации эритроцитов принимается цилиндрическая кювета. Это обусловлено тем, что экспериментальное исследование седиментации крови в цилиндрическом сосуде фотометрическим методом затруднительно цилиндр будет представлять собою линзу, что приведет к искажению цифровых фотоизображений.

Полагаем, что эквивалентный диск высотой $h$, содержащий эритроциты, движется вдоль оси $Y$ (рис. 2) со скоростью $v$. Отметим, что диск не является сплошным, имеются отверстия диаметром $d_{\mathrm{p}}$ (радиусом $\left.r_{\mathrm{p}}=d_{\mathrm{p}} / 2\right)$, символизирующие среднее межклеточное расстояние $l$. Важно заметить, что сквозь отверстия (поры - pore) в диске встречно проходит некоторое количество жидкости - раствор плазмы в случае отсутствия агрегатов (раздел 3.2). Если же эквивалентный диск содержит множество эритроцитарных агрегатов, то сквозь отверстия между ними встречно движется тот же раствор, но с некоторым количеством эритроцитов, не вошедших в состав эритроцитарных агрегатов (раздел 3.3). При таком подходе задача описания седиментации эритроцитов/агрегатов во взвеси крови сводится к нахождению параметров эквивалентного пористого диска, который оседал бы с той же скоростью $v$. Среди этих параметров величины $h, d_{\mathrm{p}}, N_{\mathrm{p}}$ - количество отверстий в диске, плотность эквивалентного диска $-\rho_{\mathrm{d}}$, скорость седиментации диска (эритроцитов/агрегатов) $v$ и, главное, связь этих параметров с исходной концентрацией эритроцитов во взвеси крови $c$.

\section{2. Моделирование седиментации эритроцитов в сильно разбавленной крови - модель коллективного движения клеток}

Рассмотрим оседание эритроцитов (сильно разбавленная кровь). При оценке плотности такого диска $\rho_{\mathrm{d}}$ следует учитывать не только плотность эритроцитов $\rho_{\mathrm{er}}$ и их количество в диске $N_{\mathrm{er}}$, но и плотность $\rho_{l}$ и количество жидкости (раствор плазмы), находящейся в порах диска с общим его объемом $V_{\mathrm{d}}=\pi R^{2} h$. Таким образом, нами рассматривается некий квазисплошной эквивалентный диск, плотность которого $\rho_{\mathrm{d}}$ имеет „промежуточное“ значение между плотностью жидкости $\rho_{1}$ и плотностью эритроцита $\rho_{\mathrm{er}}$ :

$$
\rho_{\mathrm{d}}=\rho_{1}+\frac{4 N_{\mathrm{er}} r_{\mathrm{er}}^{3}\left(\rho_{\mathrm{er}}-\rho_{1}\right)}{3 h R^{2}},
$$

где $r_{\mathrm{er}}-$ радиус „сферического“ эритроцита $\left(r_{\mathrm{er}} \approx 2.75 \mu \mathrm{m}\right)$. 
На эквивалентный диск, движущийся вдоль оси $Y$ (рис. 2), действуют силы: вес диска $M_{\mathrm{d}} g$, сила Архимеда $F_{\text {Arch }}$ и сила трения $F_{\mathrm{fr}}$, так что

$$
M_{\mathrm{d}} a=M_{\mathrm{d}} g-F_{\text {Arch }}-F_{\text {frer }},
$$

где $M_{\mathrm{d}}$ - масса эквивалентного диска, $a, g$ - ускорение движения диска и свободного падения тела соответственно. Сила $F_{\text {frer }}-$ сила трения, действующая на боковые внутренние поверхности трубок тока (следовательно, на седиментирующий диск в целом) со стороны пристеночных слоев жидкости, движущихся против направления седиментации крови:

$$
F_{\text {frer }}=k_{1} N_{\mathrm{p}} \eta_{1} S_{\text {p.lat }}\left(d v / d r_{\mathrm{p}}\right)=k_{1} N_{\mathrm{p}} \eta_{1} 2 \pi r_{\mathrm{p}} h\left(d v / d r_{\mathrm{p}}\right) .
$$

Параметр $\eta_{1}$ - коэффициент вязкости жидкости, протекающей сквозь поры в диске (раствор плазмы крови); $S_{\text {plat }}=2 \pi r_{\mathrm{p}} h-$ площадь боковой поверхности трубки тока; $r_{\mathrm{p}}$ - радиус отверстия в эквивалентном диске (радиус поры), $d v / d r_{\mathrm{p}}$ - градиент скорости потока жидкости вблизи стенки трубки тока (канал поры); $k_{1}$ - поправочный коэффициент, учитывающий отличие отверстий (пор) в диске от цилиндра (величина $k_{1}$ определяется из эксперимента). Известно, что распределение скорости течения слоев жидкости в поперечном сечении трубки тока носит квадратичный характер с максимумом скорости на оси цилиндрической трубки и практически нулевой скоростью вблизи ее стенки. Однако для простоты оценок полагаем, что распределение скорости в сечении трубки тока является линейным, симметричным относительно оси трубки с максимумом скорости в ее центре $v_{\text {max }}$. Тогда

$$
d v / d r_{\mathrm{p}}=v_{\max } / r_{\mathrm{p}}=2 v_{\text {mean }} / r_{\mathrm{p}}
$$

где $v_{\text {mean }}-$ средняя скорость течения жидкости в трубке тока $\left(v_{\text {mean }}=v_{\max } / 2\right)$. Для нахождения градиента скорости (4) и, в конечном счете, скорости оседания диска необходимо получить связь между $v_{\text {mean }}$ и скоростью седиментации диска $v_{\text {sed. }}$.

Найдем связь между средней скоростью течения жидкости в трубке тока (в отверстии диска) $v_{\text {mean }}$ и скоростью седиментации самого диска $v_{\text {sed. }}$ Количество жидкости, вытесняемой реальным, не эффективным диском (без учета пор, заполненных жидкостью) $Q_{1}$ :

$$
Q_{1}=v_{\text {sed }} S=v_{\text {sed }} \pi\left(R^{2}-N_{\mathrm{p}} r_{\mathrm{p}}^{2}\right),
$$

где $S=\pi\left(R^{2}-N r_{\mathrm{p}}^{2}\right)$ - площадь диска (без учета отверстий), выталкивающего жидкость при его седиментации в цилиндре. Это количество жидкости растекается по отверстиям:

$$
Q_{2}=N_{\mathrm{p}} v_{\text {mean }} \pi r_{\mathrm{p}}^{2}
$$

Полагаем, что жидкость несжимаема, тогда $Q_{1}=Q_{2}$ :

$$
v_{\text {sed }} \pi\left(R^{2}-N_{\mathrm{p}} r_{\mathrm{p}}^{2}\right)=N_{\mathrm{p}} v_{\text {mean }} \pi r_{\mathrm{p}}^{2}
$$

или

$$
v_{\text {mean }}=v_{\text {sed }}\left[\left(R^{2} / N_{\mathrm{p}} r_{\mathrm{p}}^{2}\right)-1\right]
$$

С учетом (8) из (4) получим

$$
d v / d r_{\mathrm{p}}=\left(2 v_{\text {mean }}\right) / r_{\mathrm{p}}=2\left(v_{\text {sed }} / r_{\mathrm{p}}\right)\left[\left(R^{2} / N_{\mathrm{p}} r_{\mathrm{p}}^{2}\right)-1\right] .
$$

Подставим (8) в (4), а результат в (2), тогда имеем

$$
M_{\mathrm{d}} a=M_{\mathrm{d}} g-F_{\text {Arch }}-k_{1} 4 \pi N_{\mathrm{p}} \eta_{1} h\left[\left(R^{2} / N_{\mathrm{p}} r_{\mathrm{p}}^{2}\right)-1\right] v_{\text {sed }} .
$$

Подставляя в (10) $M_{\mathrm{d}}=\rho_{\mathrm{d}} V_{\mathrm{d}}$, а также силу Архимеда $F_{\text {Arch, получаем }}$

$$
M_{\mathrm{d}} a=g V_{\mathrm{d}}\left(\rho_{\mathrm{d}}-\rho_{\mathrm{l}}\right)-k_{1} 4 \pi N_{\mathrm{p}} \eta_{1} h\left[\left(R^{2} / N_{\mathrm{p}} r_{\mathrm{p}}^{2}\right)-1\right] v_{\mathrm{sed}} .
$$

Сила сопротивления $\left(F_{\text {fr.er }}\right)$ в $(11)$ зависит от скорости $v_{\text {sed. }}$ Поэтому по мере возрастания скорости движения эквивалентного диска сила $F_{\text {fr.er }}$ нарастает, наступает момент баланса сил в (11), при этом ускорение $a$ обращается в нуль $(a=0)$, а скорость седиментации диска определяется как

$$
v_{\text {sed }}=\frac{g R^{2}\left(\rho_{\mathrm{d}}-\rho_{\mathrm{l}}\right)}{\left[4 k_{1} \eta_{\mathrm{l}} N_{\mathrm{p}}\left(\left(R^{2} /\left(N_{\mathrm{p}} r_{\mathrm{p}}^{2}\right)-1\right)\right]\right.} .
$$

Подставим в (12) выражение для $\rho_{\mathrm{d}}(1)$ :

$$
v_{\mathrm{sed}}=\frac{\left[\left(g N_{\mathrm{er}} r_{\mathrm{er}}^{3}\left(\rho_{\mathrm{er}}-\rho_{\mathrm{l}}\right) / 3 h\right]\right.}{\left[k_{1} \eta_{1} N_{\mathrm{p}}\left(\left(R^{2} / N_{\mathrm{p}} r_{\mathrm{p}}^{2}\right)-1\right)\right]} .
$$

Воспользуемся связью $N_{\mathrm{er}}$ с концентрацией эритроцитов $c$ в предположении, что диск представляет собой монослой $h=2 r_{\mathrm{er}}$. Тогда

$$
v_{\mathrm{sed}}=\frac{\pi g R^{2} r_{\mathrm{er}}^{3} c\left(\rho_{\mathrm{er}}-\rho_{\mathrm{l}}\right)}{3 k_{1} \eta_{1}\left(\left(R^{2} / r_{\mathrm{p}}^{2}\right)-N_{\mathrm{p}}\right)} .
$$

Итак, имеем соотношение (14), в котором $N_{\mathrm{p}}$ и $r_{\mathrm{p}}$ взаимосвязанные неизвестные. Если найти соотношение между ними, то, подставив это соотношение в (14), можно найти любой из этих параметров в зависимости от концентрации $c$. При этом следует воспользоваться экспериментальными результатами $v(c)$.

Для рассматриваемого монослоя (диска) площадь, занимаемая жидкостью, составляет

$$
S_{1}=S_{\mathrm{d}}-S_{\mathrm{er}}=\pi\left(R^{2}-N_{\mathrm{er}} r_{\mathrm{er}}^{2}\right),
$$

где $S_{\text {er }}$ - сумма максимальных площадей поперечных сечений „эритроцитов-сфер“. Поделим найденную площадь монослоя $S_{1}$ на число отверстий модели $N_{\mathrm{p}}$. Результат будет означать максимальную площадь, приходящуюся на одно отверстие (пору) в монослое модели. Тогда можно записать

$$
\pi\left(R^{2}-N_{\mathrm{er}} r_{\mathrm{er}}^{2}\right) / N_{\mathrm{p}}=k_{2} \pi r_{\mathrm{p}}^{2},
$$

где $k_{2}-$ коэффициент пропорциональности (подбирается на основании экспериментальных результатов). Откуда находим радиус отверстия $r_{\mathrm{p}}$ :

$$
r_{\mathrm{p}}^{2}=R^{2} \frac{1-2 \pi c r_{\mathrm{er}}^{3}}{k_{2} N_{\mathrm{p}}}
$$




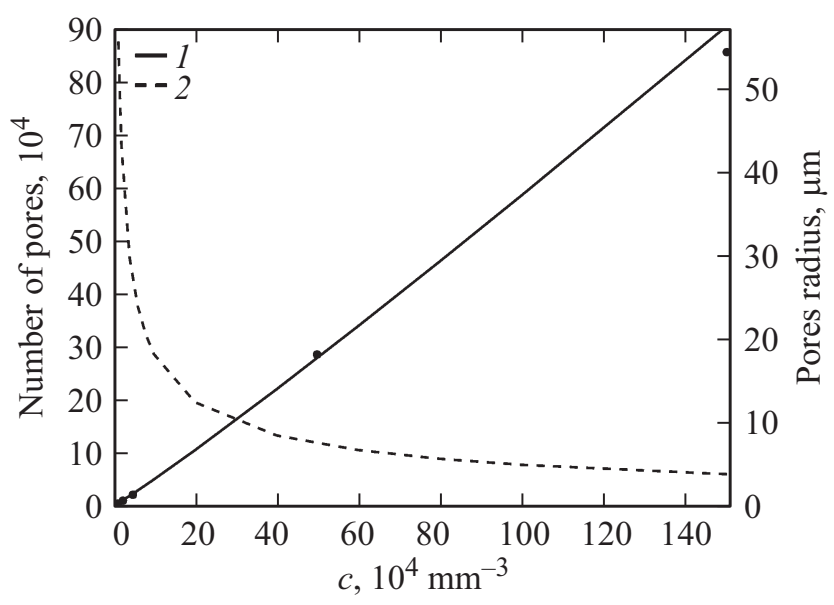

Рис. 5. Зависимость количества отверстий $N_{\mathrm{p}}$ модели эритроцитарного диска (1) и радиуса отверстий $r_{\mathrm{p}}(2)$ от концентрации эритроцитов $c$ в пробе раствора крови. Пределы концентраций эритроцитов соответствуют ограничениям рассмотренной модели седиментации эритроцитарного диска случай сильно разбавленной цельной крови. Точки - результат расчета по формулам модели, кривые - аппроксимация.

Подставив $r_{\mathrm{p}}^{2}(17)$ в (14), получаем

$$
v_{\mathrm{sed}}=\frac{\pi g R^{2} r_{\mathrm{er}}^{3} c\left(\rho_{\mathrm{er}}-\rho_{1}\right)\left[1-2 \pi c r_{\mathrm{er}}^{3}\right]}{3 k_{1} \eta_{1} N_{\mathrm{p}}\left(\left(k_{2}-1\right)+2 \pi c r_{\mathrm{er}}^{3}\right)}
$$

Подставляя в (18) экспериментально найденные значения скорости седиментации $v_{\text {sed }}$ для заданных значений концентрации $c$, найдем функцию $N_{\mathrm{p}}(c)$ (рис. 5). Аппроксимация зависимости $N_{\mathrm{p}}(c)$ дает квазистепенную функцию:

$$
N_{\mathrm{p}}(c)=a c^{b},
$$

где $a=0.223$ и $b=1.07$. На этом же рисунке приведена зависимость радиуса отверстия $r_{p}$ в дисковой модели от концентрации эритроцитов $c$ (результат подстановки (19) в (17)).

Хотя подстановка зависимости $N_{\mathrm{p}}(c)(19)$ в (18) приводит к довольно тривиальному результату - хорошее совпадение теоретического моделирования зависимости $v_{\text {sed }}$ с результатами эксперимента (рис. 6), однако из этого рисунка вытекают два интересных вывода.

1) При уменьшении концентрации крови во взвеси скорость седиментации, возрастая, устремляется к значениям скоростей оседания одиночных эритроцитов соответствующих размеров (рис. 6) как в эксперименте, так и при моделировании седиментации раствора крови;

2) При концентрациях крови свыше $30 \%$ наблюдается сильное расхождение теоретических расчетов с экспериментальными результатами. Это обусловлено тем, что при концентрациях крови выше $30 \%$ имеет место агрегация эритроцитов, которая не учитывается в рассмотренной модели седиментации. Учет агрегации эритроцитов при моделировании седиментации крови будет описан в разделе 3.3 .
Заметим, что для нахождении зависимости скорости седиментации крови от концентрации эритроцитов (рис. 6) по формуле (18) использовались следующие значения: $R=5 \mathrm{~mm}, r_{\mathrm{er}}=2.75 \mu \mathrm{m}, \rho_{\mathrm{er}}=1.092 \cdot 10^{3} \mathrm{~kg} / \mathrm{m}^{3}$, $\rho_{1} \approx 10^{3} \mathrm{~kg} / \mathrm{m}^{3}, 0.25 \% \cdot c_{0} \leq c \leq c_{0}$, где $c_{0}$ - концентрация эритроцитов в цельной крови $\left(c_{0}=5 \cdot 10^{6} \mathrm{mkl}^{-1}\right)$, $\eta_{1}=1.01 \cdot 10^{-3}$ Poise (вода при $20^{\circ} \mathrm{C}$ ). При этом наилучшее совпадение расчетной зависимости $v_{\text {sed }}(c)$ с подобной экспериментальной зависимостью имело место при $k_{1}=50000, k_{2}=1.5$.

\section{3. Моделирование седиментации эритроцитарных агрегатов - модель коллективного их движения}

Основное отличие рассматриваемой здесь задачи от задачи разд. 3.2 заключается в том, что в данном случае анализируемый слой взвеси толщиной $h$ заполнен как эритроцитами, так и их агрегатами. Моделирование седиментации такого полидисперсного слоя весьма затруднительно. Поэтому для простоты будем рассматривать слой крови, содержащий монодисперсную взвесь агрегатов, причем их размеры зависят от индивидуальных свойств образцов крови, концентрации эритроцитов в пробе $c$, а также от количества эритроцитов, входящих в агрегат $q$ (например, при нормальной СОЭ $q \approx 12$ ). Последнее следует из [34]: из „высокомолекулярных белков или высокомолекулярных веществ другой природы (декстрины) образуются межэритроцитарные „мостики“, которые как бы складывают эритроциты и $\langle\ldots\rangle$ ведут к образованию агрегатов, включающих в себя от 8 до 15 клеток, если СОЭ в пределах нормальных величин, и до десятков, сотен тысяч клеток, если СОЭ сильно увеличена“. Связь размеров эритроцитарных агрегатов и других параметров крови с величиной СОЭ также рассматривается в $[35,36]$.

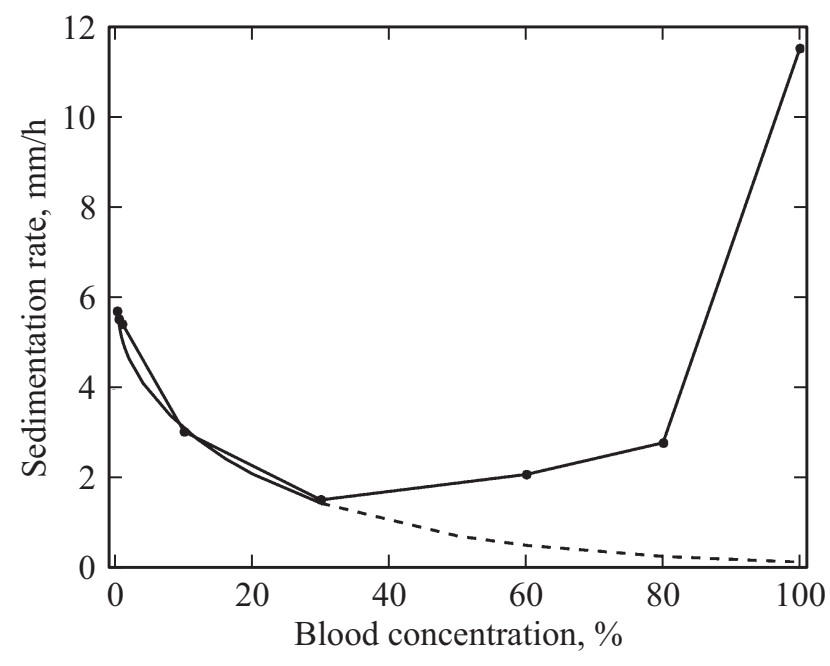

Рис. 6. Зависимость скорости седиментации крови от ее концентрации в пробе: точки - результаты экспериментов, сплошная линия — результат моделирования (формула (18)). 
Будем полагать, что в процессе седиментации слоя свободные, не вошедшие в состав агрегатов эритроциты, способны двигаться в противоположном направлении сквозь трубки тока, увлекаемые встречным по отношению к направлению седиментации потоком. При потере числа свободных эритроцитов в диске они компенсируются вновь поступившими в диск RBC из нижележащих слоев подобных дисков. Важно заметить, что движение свободных эритроцитов сквозь поры диска влияет на величину коэффициента вязкости жидкости, это будет учтено в расчетах.

Если в разд. 3.2. рассматривались эквивалентные „сферические“ эритроциты, то и здесь полагаем, что эритроцитарные агрегаты имеют форму сферы соответствующего размера (диаметра $D_{\text {ag }}=2 r_{\text {ag }}$ ). Заметим, что в настоящем разд. 3.3 практически все параметры имеют индексы ,ag“, что указывает на рассмотрение седиментации крови с учетом явления агрегации эритроцитов. Как и в разд. 3.2, в основу модели положим принцип коллективной седиментации, но не эритроцитов, а их агрегатов в диске с размерами

$$
D_{\mathrm{ag}}=d_{\mathrm{er}}(q)^{1 / 3} \text {. }
$$

По аналогии с разд. 3.2 плотность диска, содержащего эритроцитарные агрегаты, по-прежнему может быть определена по формуле (1). Однако теперь при расчете плотности диска $\rho_{\mathrm{d}}$ в формуле (1) учитывается общее количество эритроцитов $N_{\mathrm{er}}$, а не только „агрегированных“. Это обусловлено тем, что масса диска определяется общим числом эритроцитов без учета места положения эритроцитов: являются ли они свободными или связанными в агрегате.

Как и в разд. 3.2, на эквивалентный диск, движущийся вдоль оси $Y$ (рис. 2), действуют силы: вес диска $M_{\mathrm{d}} g$, сила Архимеда $F_{\text {Arch }}$ и сила трения $F_{\text {frag }}$, так что

$$
M_{\mathrm{d}}=M_{\mathrm{d}} g-F_{\text {Arch }}-F_{\text {frag }} .
$$

Сила трения с учетом наличия агрегатов $F_{\text {frag }}$ записывается в виде

$$
\begin{aligned}
F_{\text {fr.ag }} & =k_{1} N_{\text {p.ag }} \eta_{1^{\prime}} S_{\text {p.lat }}\left(d v / d r_{\text {p.ag }}\right) \\
& =k_{1} N_{\text {p.ag }} \eta_{1^{\prime}} 2 \pi r_{\text {p.lat }} h_{\mathrm{ag}}\left(d v / d r_{\text {p.ag }}\right),
\end{aligned}
$$

где $N_{\mathrm{p}}$ - количество отверстий (пор, трубок тока) в модели слоя крови, $r_{\text {p.ag }}-$ радиус отверстия в диске, $S_{\text {p.lat }}=2 \pi r_{\text {p.ag }} h-$ площадь боковой поверхности трубки тока, $d v / d r_{\text {p.ag }}$ - градиент скорости потока жидкости вблизи стенки трубки тока (канал поры) для слоя, содержащего агрегаты. Отличие $\eta_{1}^{\prime}$ от $\eta_{1}$ (разд. 3.2) заключается в том, что здесь $\eta_{1}^{\prime}$ соответствует раствору плазмы крови, содержащему некоторое количество свободных эритроцитов, не вошедших в состав агрегатов.

Для слоя, включающего эритроцитарные агрегаты, в (4) следует ввести переобозначение

$$
d v / d r_{\text {p.ag }}=2 v_{\text {mean.ag }} / d r_{\text {p.ag }} .
$$

С учетом (21)-(23) по аналогии с (10) получим

$$
M_{\mathrm{d}} a=g V_{\mathrm{d}}\left(\rho_{\mathrm{d}}-\rho_{\mathrm{l}}\right)-k_{1} N_{\text {p.ag }} \eta_{1^{\prime}} 4 \pi r_{\text {p.ag }} h_{\text {ag }}\left(v_{\text {mean.ag }} / r_{\text {p.ag }}\right) \text {. }
$$

Связь между средней скоростью течения жидкости в трубке тока (в отверстии диска) $v_{\text {mean.ag }}$ и скоростью седиментации самого диска $v_{\text {sed }}$ определена в $(8)$, однако с учетом переобозначений

$$
v_{\text {mean.ag }}=v_{\text {sed.ag }}\left[\left(R^{2} /\left(N_{\text {p.ag }} r_{\text {p.ag }}^{2}\right)-1\right] .\right.
$$

Подставим (25) в (24):

$$
\begin{aligned}
M_{\mathrm{d}} a= & g V_{\mathrm{d}}\left(\rho_{\mathrm{d}}-\rho_{\mathrm{l}}\right) \\
& -k_{1} N_{\text {p.ag }} \eta_{1^{\prime}} 4 \pi h_{\mathrm{ag}}\left(v_{\text {sed.ag }}\left[\left(R^{2} / N_{\text {p.ag }} r_{\text {p.ag }}^{2}\right)-1\right]\right) .
\end{aligned}
$$

Из рис. $2, e-h$ и рис. $3, b$ видно, что слои взвеси крови с исходными концентрациями крови от 30 до $100 \%$ седиментируют практически равномерно. Тогда ускорение $a$ в (26) можно положить равным нулю $(a=0)$, а скорость седиментации диска определится как

$$
v_{\text {sed.ag }}=\frac{\left[g r_{\mathrm{er}}^{2} N_{\mathrm{er}}\left(\rho_{\mathrm{er}}-\rho_{\mathrm{l}}\right)\right]}{\left.3 k_{1} \eta_{1^{\prime}}\left(\left(R^{2} / r_{\text {p.ag }}^{2}\right)-N_{\text {p.ag }}\right)\right]} .
$$

Выше отмечалось, что не все эритроциты монослоя входят в состав агрегатов, часть их движется сквозь поры слоев (трубки тока) в противоположном направлении относительно направления седиментации крови. Количество таких свободных эритроцитов $c^{\prime}$ зависит от их исходной концентрации $c$, а также от числа эритроцитов, связанных в агрегатах, так что $c^{\prime}=c-q c_{\mathrm{ag}}$. Здесь $c_{\mathrm{ag}}$ - концентрация агрегатов в эффективном диске, a $q c_{\mathrm{ag}}$ - общее количество эритроцитов, вошедших в общее число агрегатов в объеме диска.

Напомним, что в случае сильного разведения крови (раздел 3.2) полагалось, что свободные эритроциты отсутствуют во встречном потоке жидкости сквозь „трубки тока“ в монослое (поры). Тогда $\eta_{1}$ - вязкость раствора плазмы. В данном случае при больших исходных концентрациях эритроцитов сквозь отверстия в диске вместе с раствором плазмы движутся те эритроциты, которые не вошли в состав агрегатов. Тогда вязкость порции раствора крови, проходящей сквозь поры монослоя, будет зависеть от концентрации свободных эритроцитов $\eta_{1}^{\prime}=\eta_{1} \exp \left(k_{0} c^{\prime}\right)=\eta_{1} \exp \left(k_{0}\left(c-q c_{\mathrm{ag}}\right)\right)[28,32,33]$, где $k_{0}$ - коэффициент, подбираемый для наилучшего согласования экспоненциальной зависимости коэффициента вязкости крови от ее RBC-концентрации. В [28,32,33] коэффициент $k_{0}$ оказался равным $k_{0} \approx 3.4805 \cdot 10^{-7} \mathrm{~mm}^{3}$. С учетом изложенного перепишем (27):

$$
v_{\text {sed.ag }}=\frac{\left[g r_{\mathrm{er}}^{2} N_{\mathrm{er}}\left(\rho_{\mathrm{er}}-\rho_{\mathrm{l}}\right)\right]}{\left.\left[3 k_{1} \eta_{1} e^{\left(k_{0}\left(c-q c_{\mathrm{ag}}\right)\right)}\left(\left(R^{2} / r_{\text {p.ag }}^{2}\right)-N_{\text {p.ag }}\right)\right]\right)},
$$

или с учетом $N_{\mathrm{er}}=c V_{\mathrm{d}}=c \pi R^{2} 2 r_{\mathrm{ag}}$

$$
v_{\text {sed.ag }}=\frac{\left[2 \pi g r_{\mathrm{er}}^{3} R^{2}(q)^{1 / 3} c\left(\rho_{\mathrm{er}}-\rho_{1}\right)\right]}{\left.\left[3 k_{1} \eta_{1} e^{\left(k_{0}\left(c-q c_{\mathrm{ag}}\right)\right)}\left(\left(R^{2} / r_{\text {p.ag }}^{2}\right)-N_{\text {p.ag }}\right)\right]\right)} .
$$


По аналогии с (17) установим связь между количеством отверстий (пор) в дисковой модели $N_{\text {p.ag }}$ и их средним радиусом $r_{\text {p.ag }}$ для случая агрегации эритроцитов:

$$
r_{\text {p.ag }}^{2}=\frac{R^{2}\left(1-2 \pi q r_{\mathrm{er}}^{3} c_{\mathrm{ag}}\right)}{k_{2} N_{\text {p.ag }}}
$$

Подставляя (30) в (29) и преобразуя, получаем

$$
v_{\text {sed.ag }}=\frac{2 \pi g r_{\mathrm{er}}^{3} R^{2}(q)^{1 / 3} c\left(\rho_{\mathrm{er}}-\rho_{1}\right)\left(1-2 \pi q r_{\mathrm{er}}^{3} c_{\mathrm{ag}}\right)}{3 k_{1} \eta_{1} e^{\left(k_{0}\left(c-q c_{\mathrm{ag}}\right)\right)} N_{\mathrm{p} . \mathrm{ag}}\left(\left(k_{2}-1\right)+2 \pi q r_{\mathrm{er}}^{3} c_{\mathrm{ag}}\right)} .
$$

Для определения концентрации агрегатов $c_{\mathrm{ag}}$ в (31) разумно полагать, что

1) количество монодисперсных агрегатов в рассматриваемом монослое возрастает с увеличением концентрации эритроцитов $c$;

2) концентрация агрегатов $c_{\text {ag }}$ максимальна при стремлении концентрации эритроцитов $c$ к их концентрации для цельной крови $c_{0}\left(c<c_{0}\right.$ и $\left.c \rightarrow c_{0}\right)$;

$3)$ концентрация агрегатов $c_{\text {ag }}$ стремится к нулю при стремлении концентрации эритроцитов $c$ к нулю $\left(c<c_{0}\right.$ и $c \rightarrow 0)$.

Одним из возможных вариантов функции, удовлетворяющим таким условиям, является сигмоида вида

$$
\sigma(c)=\frac{1}{1+e^{\frac{c_{0}-c}{c}}} .
$$

Тогда концентрация агрегатов $c_{\mathrm{ag}}$ может быть определена как

$$
c_{\mathrm{ag}}=2 c \sigma(c) / q .
$$

Здесь $k_{4}$ - поправочный коэффициент пропорциональности для наилучшего согласования расчетов модели с экспериментом. Объединяя (32) и (33), получим

$$
c_{\mathrm{ag}}=\frac{2 c}{q\left(1+e^{\frac{c_{0}-c}{c}}\right)} .
$$

Функция (34) удовлетворяет вышеприведенным требованиям:

- если $c \rightarrow 0$, то концентрация агрегатов $c_{\mathrm{ag}} \rightarrow 0$;

- если $c \rightarrow c_{0}$, то $c_{\mathrm{ag}} \rightarrow(c / q)=\max$.

Зависимость количества агрегатов $c_{\text {ag }}$ от исходной концентрации эритроцитов в диске представлена на рис. 7, $a$. Представленные оценки (рис. 7, $a$ ) показывают, что вПлоть до концентраций эритроцитов $c$, соответствующих концентрациями крови 20-30\%, агрегаты практически не образуются, однако при больших концентрациях $c$ процесс агрегации быстро нарастает.

Подстановка (34) в (31) позволяет найти связь между скоростью оседания слоя крови $v_{\text {sed.ag }}(c)$, содержащего агрегаты и свободные эритроциты, с концентрацией эритроцитов в пробе $c$. Однако заметим, что в этой зависимости $v_{\text {sed.ag }}(c)$ остается неизвестной функция $N_{\text {p.ag }}(c)$.
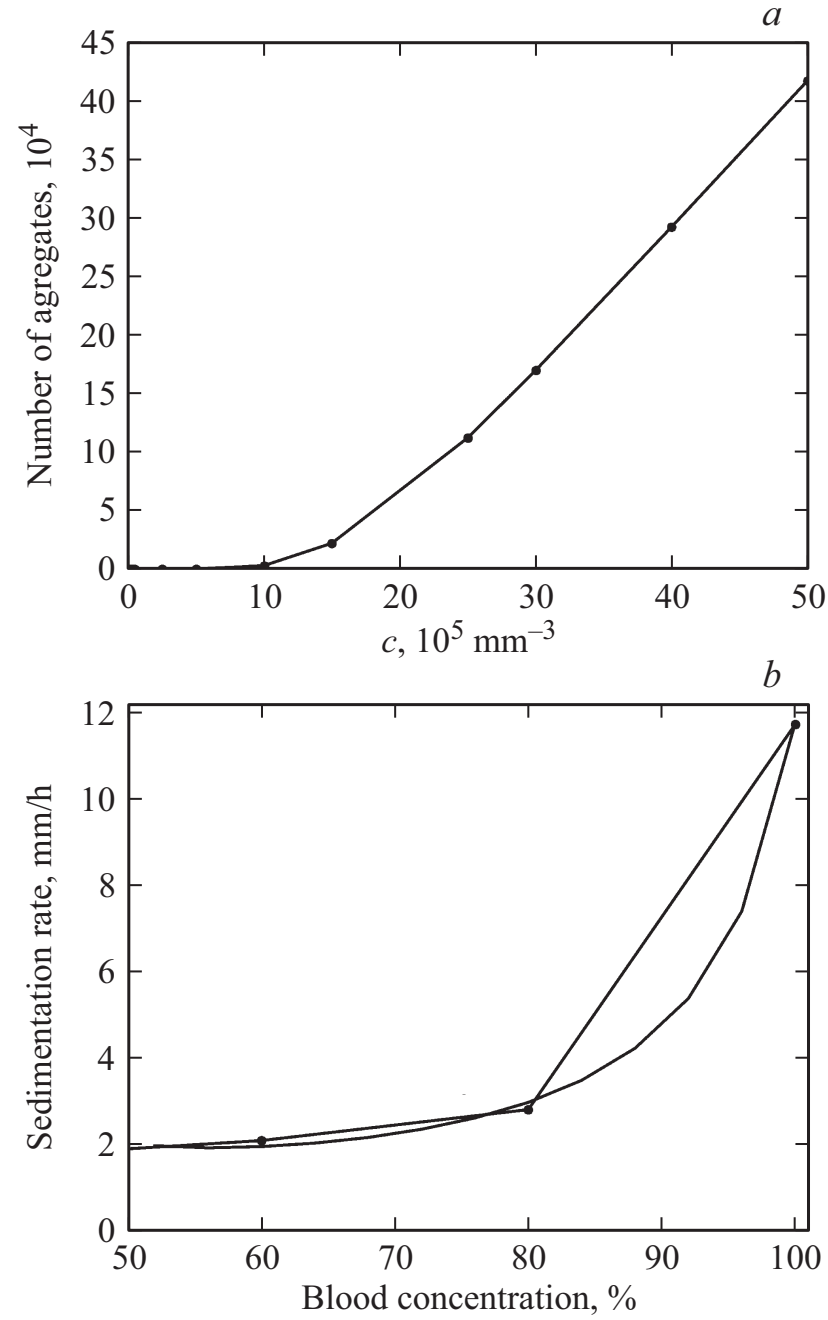

Рис. 7. Зависимость количества агрегатов в диске $c_{\mathrm{ag}}(a)$, а также скорости седиментации крови $v_{\text {sed.ag }}(b)$ от начальной концентрации эритроцитов: (a) точки - результаты расчетов (34), $q=12$; $(b)$ точки - результаты эксперимента, кривая - моделирование с учетом RBC-агрегации при слабом разведении образцов крови. Для цельной крови полагалось, что концентрация эритроцитов составляет $5 \cdot 10^{6} \mathrm{~mm}^{-3}$.

Вид этой функции $N_{\text {p.ag }}(c)$ можно найти на основании эксперимента. Для этого следует в (31) подставить значения концентраций $c$ и соответствующие им измеренные скорости $v_{\text {sed.ag }}(c)$ (рис. 7, $b$ ). Тогда (29) позволит определить функцию $N_{\text {p.ag }}(c)$ для избранных значений констант $k_{1}, k_{2}$ (рис. 8). Полученная зависимость $N_{\text {p.ag }}(c)$ в пределах $c=(2.5-5) \cdot 10^{6} \mathrm{~mm}^{-3}$ аппроксимировалась рядом: $N_{\text {p.ag }}(c)=-3.345 \cdot 10^{-7} c^{2}+2.35 \cdot c-3 \cdot 10^{6}$. Далее с использованием $N_{\text {p.ag }}(c)$ и (34) нетрудно определить зависимость радиуса отверстий дисковой модели $r_{\text {p.ag }}$ от концентрации эритроцитов $c$ (рис. 8).

Из рис. 8 видно, что с ростом концентрации эритроцитов, вплоть до $4 \cdot 10^{6} \mathrm{~mm}^{-3}$, количество отверстий $N_{\text {p.ag }}$ в дисковой модели эритроцитарного монослоя возрастает

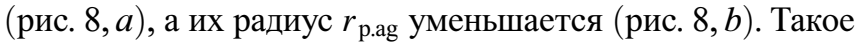




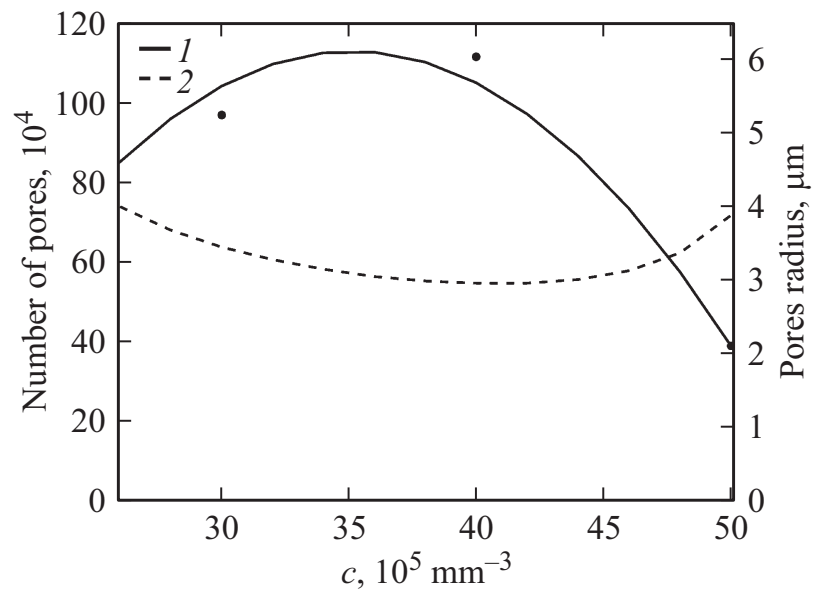

Рис. 8. Зависимость количества отверстий в дисковой модели $N_{\text {p.ag }}(1)$ и их радиус $r_{\text {p.ag }}(2)$ от концентрации эритроцитов $c$ : точки - результаты расчетов (степенной ряд для $N_{\text {p.ag }}$ и формула (30)) для $r_{\text {p.ag; }}$ кривые - аппроксимации.

поведение $N_{\text {p.ag }}(c)$ и $r_{\text {p.ag }}(c)$ довольно естественно: чем выше концентрация эритроцитов в пробе, тем больше вероятность образования агрегатов разных размеров, их число возрастает, а расстояние между ними сокращается. Вслед за этим в модели (эквивалентном диске) $N_{\text {p.ag }}$ увеличивается, а $r_{\text {p.ag }}$ соответственно снижается.

Однако в диапазоне концентраций эритроцитов $4 \cdot 10^{6} \leq c \leq 5 \cdot 10^{6} \mathrm{~mm}^{-3}$ зависимость этих параметров обратная (рис. 8). Это обусловлено тем, что в этом диапазоне значений межклеточное расстояние $l_{\mathrm{er}}$ оказывается чрезвычайно малым: диапазону RBC-концентраций (4-5) $\cdot 10^{6} \mathrm{~mm}^{-3}$ соответствуют среднестатистические расстояния порядка $0.8-0.35 \mu \mathrm{m}$. Столь малое расстояние $l_{\mathrm{er}}$ в этом диапазоне концентраций повышает вероятность образования агрегатов (рис. 7,a). Тогда в силу ограниченности количества эритроцитов в единице объема расстояние между агрегатами $l_{\text {ag }}$ возрастает, а их число уменьшается. Адекватно ведут себя и параметры $N_{\text {p.ag }}$ и $r_{\text {p.ag }}$ модели (эквивалентного диска).

\section{4. Заключение}

Экспериментально определена зависимость скорости седиментации раствора крови от концентрации эритроцитов. Показано, что скорость седиментации существенно (в несколько раз) возрастает при сильном или, наоборот, при слабом разведении цельной крови. При этом минимум скорости оседания крови лежит в диапазоне концентраций крови в растворе 30-50\%. Предложено объяснение экспериментально выявленной закономерности - повышение скорости седиментации крови в вышеупомянутых случаях связано с увеличением межклеточного расстояния и, следовательно, с уменьшением силы трения, оказываемой встречным потоком раствора плазмы на движение эритроцитов и/или их агрегатов.
Заметим, что увеличение межклеточного расстояния в случае сильно разбавленной или почти цельной крови происходит по-разному: в первом случае имеет место автоматическое снижение RBC-концентрации при разбавлении крови физраствором, а во втором - за счет агрегации эритроцитов.

Цифровая фоторегистрация кинетики седиментации крови для разных уровней ее разведения физраствором позволила обнаружить ранее отмеченную особенность [4] (разд. 1) - процесс седиментации крови стартует не сразу, а после некоторого интервала времени, в нашем случае вплоть до $\sim 50 \mathrm{~min}$. Причем увеличение концентрации эритроцитов сокращает время запаздывания седиментации. В работе рассмотрены два подхода к объяснению механизма этого явления.

Предложенная математическая модель седиментации крови в виде оседания эквивалентного эритроцитарного диска в определенной степени подобна отмеченной в разд. 1 „сетевой“ модели строения образцов крови модели С.Д. Балаховского. Как и в модели С.Д. Балаховского, встречный поток проходит сквозь отверстия (поры) в эквивалентном диске (в „сети“ ${ }^{6}$. Предложенная дисковая модель рассмотрена в двух вариантах: для сильно разбавленных образцов крови, когда узлами „сети“ являются эритроциты (или „сети“ отсутствуют вовсе, а седиментируют индивидуальные, свободные эритроциты). Второй вариант - слабо разбавленные пробы крови - эквивалентный диск содержит эритроцитарные агрегаты, а встречный поток представляет собой раствор плазмы с некоторым количеством эритроцитов, не вошедших в состав агрегатов. Оба варианта теоретической модели седиментации крови нашли удовлетворительное согласие с экспериментальными результатами.

Помимо общего научного интереса настоящее исследование может иметь некоторое прикладное значение. Так, в работе экспериментально и модельно показано, что скорость седиментации крови зависит от начальной концентрации крови, агрегационной способности образца, вязкости плазмы, степени разведения пробы крови. Таким образом, СОЭ - многофакторный параметр испытуемого образца крови для решения задач гемодиагностики. Видимо, это обстоятельство приводит к определенной неоднозначности данного метода в диагностике (отмечено в разд. 1 и [8]). В этой связи представляется целесообразным перед анализом СОЭ проводить ряд дополнительных исследований. Например, определение начальной концентрации эритроцитов в пробе крови с последующим введением нормировочного коэффициента при проведении СОЭ-анализа с этим образцом.

\section{Благодарности}

Авторы выражают признательность проф. Воейкову В.Л. за стимулирование интереса к данной тематике, а также за предоставление литературы, необходимой для выполнения работы. 


\section{Финансирование работы}

В.В. Тучин выражает благодарность гранту Правительства Российской Федерации 14.Z50.31.0044 за поддержку.

\section{Соблюдение этических стандартов}

Настоящая статья не содержит каких-либо исследований с участием людей в качестве объектов исследований.

\section{Список литературы}

[1] Biernacki E. // Z. f. Physiolog. Chem. 1894. Bd. 19. S. 179.

[2] Westergren A. // Acta Med. Scand. 1921. V. 54. P. 247-281.

[3] Reza Hashemi, Alireza Majidi, Hassan Motamed, Afshin Amini, Fares Najari, Ali Tabatabaey // Emergency. 2015. V. 3. N 2. P. 50-53.

[4] Mehrun Nisa, Samina Zaman // Proceeding S.Z.P.G.M.I. 2003. V. 17. N 2. P. 71-73.

[5] Liseth Siemons et al. // BMC Musculoskeletal Disorders. 2014. V. 15. P. 368. http://www.biomedcentral.com/1471$2474 / 15 / 368$

[6] Farhana Shahzad, Shahzad Tawwab, Afia Abbas. // J. Ayub. Med. Coll. Abbottabad. 2009. V. 21. N 3. P. 1.

[7] Rühenstroth-Bauer G., Schedler K., Scherer $R$, Vesterberg O. // J. Clin. Chem. Clin. Biochem. 1990. V. 28. P. $845-850$.

[8] Воейков В.Л. // Успехи физиол. наук. 1998. Т. 29. № 4. C. $55-73$.

[9] Talstad I., Haugen H.F. // Scand. J. Clin. Lab. Invest. 1979. V. 39. N 6. P. 519-524.

[10] Xing Shi, Guang Lin. // Numerical Mathematics: Theory, Methods and Applications. 2014. V. 7. N 4. P. 512-523.

[11] Hung W.T., Collings A.F. // Phys. Med. Biol. 1994. V. 39. P. $1855-1873$.

[12] Fabry T.L. // Blood. 1987. V. 70. N 5. P. 1572-1576.

[13] Voeikov V.L., Goncharenko A.I., Goncharenko S.A., Kaganovskii I.P. // The 3rd European Medical and Biological Engineering Conference. 2005, EMBEC'05. Prague, Czech Republic. IFMBE Proc. 2005. V. 11. N 1. P. 1727-1983.

[14] Воейков В.Л., Буравлева Е.В., Кондаков С.Э. // Вестн. Моск. ун-та. Сер. 2. Химия. 2012. Т. 53. № 6. С. 413-416.

[15] http://www.advensum.com/catalog/encyclopedia_technologies /laboratory/1528

[16] Смоляр К.A. http://www.veterinars.com/dokladu/oметодах-определения-скорости-оседа.html. Опубликовано 01.05.2016.

[17] Ismailov R.M. , Shevchuk N.A., Khusanov H. // BioMedical Engineering OnLine. 2005. V. 4. P. 24. doi 10.1186/1475925X-4-24

[18] Bürger R., Wendland W.L. // J. Engineering Mathematics. 2001. V. 41. N 2. P. $101-116$.

[19] Лосев Е.С. // Биофизика. 1992. Т. 37. Вып. 6. С. 1.

[20] Pribush A., Meyerstein D., Meyerstein N. // Colloids and Surfaces B: Biointerfaces 2010. V. 75. P. 214-223.

[21] Fenech M., Garcia D., Meiselman H.J., Cloutter G. // Ann. Biomed. Engineering. 2009. V. 37. N 11. P. 2299-2309. doi 10.1007/s10439-009-9775-1
[22] Дубровский В.А., Дворецкий К.Н., Марков С.В. // Проблемы оптической физики и биофотоники. SFM-2017. Саратов: „Новый ветер“, 2017. С. 20-28.

[23] Zlonis M. // Clin. Lab. Med. 1993. V. 13. P. 787-800.

[24] Stokes G.G. Mathematical and Physical Papers. Cambridge: AT, The University Press, 1980.

[25] Syoten Oka // Biorheology. 1985. V. 22. P. 315-321.

[26] Normatov T.D., Khusanov I.N. // Nauka. 2001. V. 5. P. 35-38.

[27] Балаховский С.Д. Реакция оседания эритроцитов. М.-Л.: ГИЗ, 1928. 149 с.

[28] Дубровский В.А., Дворецкий К.Н., Балаев А.Э. // Акустический журнал. 2004. Т. 50. № 2. С. 184-192.

[29] Дубровский В.А., Долмашкин А.А. // Медицинская техника. 2012. № 2. С. 24-30.

[30] Дубровский В.А., Забенков И.В., Торбин С.О. // Медицинская техника. 2013. № 3. С. 14-17.

[31] Doubrovski V.A., Ganilova Yu.A., Zabenkov I.V. // J. Biomed. Opt. 2014. V. 19. N 3. doi 10.1117/1.JBO.19.3.036012

[32] Doubrovski V.A., Dvoretski K.N. // Ultrasound in Medicine \& Biology. 2000. V. 26. N 4. P. 655-659.

[33] Дворецкий К.Н. Автореф. канд. дис. 2004.

[34] Алексеенко И.Ф. // Конспект врача. 2013. № 19. С. 379. https://studfiles.net/preview/535508

[35] Bishop J.J., Nance P.R., Popel A.S. // Am. J. Physiol. Heart. Circ. Physiol. 2004. V. 286. N 1. P. 113-120. https:/www.ncbi.nlm.nih.gov/pubmed/12969894

[36] Boynard M., Lelievre J.C. // Biorheology. 1990. V. 27. N 1. P. 39-46. https://www.ncbi.nlm.nih.gov/pubmed/1694460 